
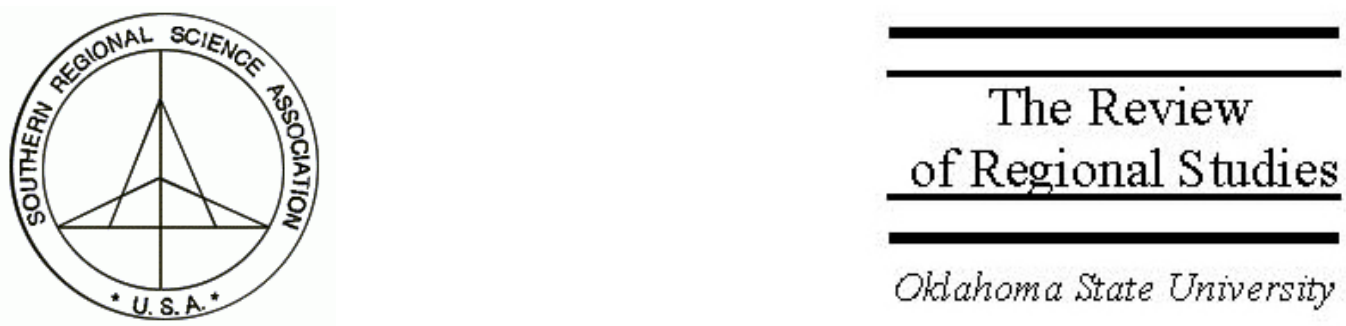

\title{
The Spatial Economy of Gender-Based Occupational Segregation
}

\author{
M. Rose Olfert \\ Department of Agricultural Economics, University of Saskatchewan, 51 Campus Drive, \\ Saskatoon, SK, S7N 5A8, CA, e-mail: rose.olfert@usask.ca
}

Dianne M. Moebis

Department of Finance, Government of Nunavut, P.O. Box 1000, Station 330, Iqaluit, NU XOA OHO, CA

\begin{abstract}
Occupational segregation by gender persists in spite of improvements in labor market gender equality over the past 40 years. In this paper a simple index of occupational segregation, the DIndex, computed for each of the 288 census divisions in Canada for the year 2000 is regressed on a measure of "rurality," along with the standard explanations. The rurality variable is included to capture the influence of spatial variations in access to services and employment opportunities. Results indicate a strong influence of rurality, even when industrial composition is controlled for. Education attainment gaps and the presence of children are also significant.
\end{abstract}

Keywords: Occupational segregation; Rural-urban; Spatial variation

JEL classification: R23; R38; J78

Acknowledgements: I thank two anonymous referees, Timothy Beatty, Mark Partridge, and Dan Rickman for helpful comments on earlier versions of this paper. 


\section{INTRODUCTION}

The past 40 years have seen significant improvements in labor market gender equality in OECD countries, as female participation rates have increased and the wage gap has narrowed (Freeman 2000; Fortin and Huberman 2002b). In spite of this, occupational segregation by gender persists, with women highly concentrated in certain occupations (Fortin and Huberman 2002a; Maruani 2000; J.A. Preston 2000; A. Preston 2004, 2003). Potential explanations for the observed segregation include personal preferences, systemic discrimination, human capital differences, access to childcare and transportation services, and family choices.

Occupational segregation is a public policy concern if the observed segregation is indicative of barriers to factor mobility. Public policies designed to address barriers range from affirmative action to measures to equalize human capital characteristics. Concerns remain that the markedly dissimilar occupational distributions of males and females are sub-optimal labor market outcomes due to systemic hindrances to occupational choice. Further, occupational segregation has been found to be significantly responsible for wage and income inequality (Bridges 2003; Fortin and Huberman 2002a).

The most common measure of occupational segregation, the Duncan Dissimilarity Index (or D-Index), dates back to 1955 (Duncan and Duncan 1955). Subsequent innovations have generated improvements in the accuracy of the measurement, the introduction of multivariate influences, and alternative approaches to conceptualizing and measuring occupational segregation (Gross 1968; Hutchens 2001, 2004; Meng and Miller 1995; Rawlston and Spriggs 2002; Spriggs and Williams 1996). While the measurement of occupational segregation has been the subject of serious and persistent investigation, the empirical work has focussed less on estimating the determinants of the measured indices. ${ }^{1}$ An explicit estimation of the relationship between the occupational segregation measures and their determinants will lead to a better understanding of occupational choice determinants and, potentially, policy instruments.

Further, although the seminal work by Duncan and Duncan (1955) included residential location (within an urban context) as a determinant of occupational segregation, a systematic consideration of the spatial dimensions of occupational segregation across the urban-rural continuum is largely absent in the literature. Yet spatial differences in industrial structures, in child care services, the presence of the full range of occupations, cost of distance in transportation and time, and variations in the industrial distribution of the local economy would seem to be major determinants of occupational choice and may impact females differently than males. Explicit consideration of rural-urban spatial variables as determinants may thus offer an explanation for the persistence of

\footnotetext{
${ }^{1}$ An exception is Bloomquist (1990), where segregation measures are regressed on variables including local labor market characteristics.
} 
occupational segregation. In terms of a policy response, a targeted approach could address region-specific types and degrees of occupational segregation.

In this paper an index of occupational segregation, the D-Index, computed for each of 288 census divisions in Canada for the year 2000 is regressed on explanatory variables to determine their effects on the index values. Included among the explanatory variables is a measure of the "rurality" of the region to capture the influence of spatial variations. Results indicate a strong influence of the rurality variables, even when industrial composition is controlled for. Education attainment gaps and the presence of children are also found to be significant.

The paper is organized as follows. Section 2 presents the conceptual framework; Section 3 provides a brief review of the occupational segregation measurement literature. This is followed by the presentation of the empirical model and a description of the data and methodology. In Section 6, the empirical results are presented, followed by conclusions and policy implications.

\section{CONCEPTUAL FRAMEWORK}

Labor market outcomes in terms of occupational distributions of males and females reflect both supply-side occupational choices and demand-side influences. On the supply side, individuals or families make decisions regarding the quantity and quality of time allocations to the labor market to maximize utility. Leisure hours are traded off for income earned or command over consumption goods based on individual (or household) preferences, subject to a constraint defined by the market exchange rate of hours for pay (wage rate) (Becker 1965, 1985; Gronau 1977; Honig and Hanoch 1978; Kooreman and Kapteyn 1987).

While the household time allocation model was initially employed primarily to explain labor force participation, it is also a useful framework for representing decisions regarding occupational choice. Preferences will be influenced by the presence and number of children, education levels, the distribution of work commitments over a lifetime, preferences in regard to flexibility, intensity of commitment, travel requirements, etc. (Brown, Moon, and Solith 1980). Constraints, sometimes represented by a "reservation wage," include access to goods and services affecting time requirements, time spent commuting, lifetime and life cycle influences relating to child care, non-labor income, income of the spouse (if present). The occupational preferences of individuals, embodied in labor supply decisions, are part of the utility maximizing decisions of individuals.

On the demand side, labor productivity, often represented by human capital measures at the individual level, will be a primary influence. Human capital is the personal investment an individual makes to increase productivity (Schultz 1961). Unique to an individual, human capital is not transferable from one person to another, and there is a finite supply for each person (Blinder and Weiss 1976). Investments that can be undertaken to increase a person's human capital include formal education, formal on-the-job 
training, job experience, government and private training programs, health expenditures, job search, and migration (Glaister 1977). Governments contribute to human capital formation by providing universal services such as education and health care. Businesses invest in their employees' human capital by providing benefits like job-related training, fitness programs, or employee relocation assistance programs.

According to human capital theory, differences in earnings and/or occupations occur because of differences in the investment in human capital (Becker 1985; Mincer and Polachek 1974). Similar levels of human capital would lead to the expectation of similar occupations and earnings. Earnings differentials are self-correcting through the mobility (occupational and geographic) of labor force members. Barriers of various kinds may inhibit this mobility, resulting in persistent "wage gaps.”

When occupational and earnings differentials exist, discerning whether these are attributable to differences in human capital requires measurement of differences in formal education, age, health, place of residence, presence of children (and their ages), and marital status. Characteristics such as family attitudes and preferences (household utility), family income, country of origin, or first language are also important factors in measuring human capital (Becker 1975, 1985; Bloomquist 1990; Kidd and Shannon 1994; McGoldrick and Robst 1996; Preston 1997; Robinson and Tomes 1985). These characteristics are thought to influence both the quality and quantity of human capital investment.

As workers become more similar in the kinds and amounts of human capital they possess, wage gaps and male- or female-dominated occupations should become less prevalent. In the rural-urban context, rural and urban labor force members with similar human capital, all else equal, would be expected to have similar earnings levels and be found in similar occupations. If, however, there is no convergence in the occupational distribution of males and females, there must be other factors influencing occupational segregation or differential returns to labor.

Beyond the neoclassical human capital models, additional frameworks within which occupational segregation may be considered include dual economy, internal labor market, and systemic discrimination. Robert Averitt's (1968) theory of segmentation (dual economy) suggests there are two distinct and separate economies operating within the larger economy, a core and a periphery. The core economy is characterized by its capital intensity, high profit margins, high market concentration, and product diversification as well as high levels of job stability (Beck, Horan, and Tolbert 1980). Because of its use of technology and firm-specific production techniques, the core economy requires a stable, highly skilled workforce. As an incentive for stability, firms provide on-the-job training, relatively high wages, and internal job mobility (Villa 1986).

The periphery (secondary) economy is based on firms producing nondurable manufacturing and agricultural products. It includes much of the retail trade and low-end service industries. This sector is less capital intensive and is characterized by low profit 
margins, low-skilled job requirements, and highly competitive markets. Employee turnover is high, working conditions are poor, and wages are low. There is very little skill development and almost no internal mobility available to employees. According to Averitt (1968), this segment is mainly the domain of women, minorities, and the young.

Doeringer and Piore (1971) examined the labor markets within the dual economy sectors for their explanations of occupational segregation. Their internal labor market theory posits that labor markets are not only divided by the primary and secondary sectors of the dual economies, but are further segmented into markets at the industry and even the firm level.

Even within the human capital framework, structural characteristics of labor markets are increasingly recognized as being important (Beck, Horan, and Tolbert 1980; Norcliffe 1993; Bloomquist 1990). Factors such as wage rates, participation rates, and place of residence (rural/urban) have been identified as being important structural characteristics in determining occupational opportunities. Also included have been the local unemployment rate and the availability of a skilled labor force (Bloomquist 1990; Bokemeier, Sachs, and Keith 1983; Deseran, Li, and Wojtkiewicz 1993).

Another explanation for occupational segregation is that the sexual division of labor is based upon the differing roles that men and women play because of biological factors. According to this sexual division of labor theory, occupational segregation should decline in industries where physical attributes of workers become less important. This is not apparent at the aggregate level (Walby 1988). In addition, Fuchs (1989) points out that occupational segregation occurs in both rapidly growing industries and stagnant ones.

Feminist or gender theories focus on the possibility that patriarchy and women's subordinate position in society, stereotyping, and systemic discrimination are the reasons for persistent occupational segregation between men and women. Bergmann (1974) offers a discrimination explanation of employer choice in hiring predominantly women into certain occupations. Where there are barriers to certain occupations, the supply of women in occupations without barriers increases, lowering the relative earnings in these occupations. Beller (1982) offers empirical support for the discrimination hypothesis by showing that U.S. federal government legislation aimed at reducing discrimination increased the probability of women being employed in male-dominated occupations. Anker (1997), in an overview of occupational segregation by sex, points out that common stereotypes of women's responsibilities (household work and childcare) contribute to gender-based discrimination against women. The stereotypes, mirrored in "female" occupations, result in women acquiring less human capital and having less labor market experience.

The Canadian legislative context for evaluating occupational segregation includes both federal and provincial acts (Agocs 2002). The federal Employment Equity Act of 1986 and its 1996 revision, the Federal Contractors Program (1986), sections of the Canadian Human Rights Act (1978), and the Charter of Rights and Freedoms of the 
Constitution Act (1982) all represent responses to systemic discrimination in the workplace. Four groups have been designated under the employment equity legislation and policy - women, visible or racial minorities, aboriginal peoples, and persons with disabilities. While the federal acts are explicitly concerned with the federal jurisdiction and suppliers to the federal government, most provinces have passed similar legislation and many public and some private institutions responded with voluntary policies. In 1987, Quebec passed its own employment equity legislation; and in 1994, Ontario followed with comprehensive employment equity legislation. Both federally and provincially, pay equity legislation complements the employment equity legislation. Agocs (2002) reports a persistent gap between employment equity policy and practice due to a disappointing level of implementation and enforcement.

\section{OCCUPATIONAL SEGREGATION MEASUREMENT}

The first concrete attempts to measure segregation appeared in the early 1950s with the ground-breaking paper on the link between occupational groups and spatial location of residence by Duncan and Duncan (1955). An index of dissimilarity was constructed to measure the spatial distribution of occupations. First, the percentage of all workers in each area that are in each occupational group is calculated. The index of dissimilarity is then one-half the sum of the absolute values of the differences between the locationspecific distributions, summed over all occupations.

$$
D=\frac{1}{2} \sum_{i=1}^{k}\left|\frac{W 1_{i}}{W 1}-\frac{W 2_{i}}{W 2}\right|
$$

where W1 is the workers in area one, W2 is the workers in area 2, and $i$ is the occupation.

The index shows the percentage of workers in area 1 that would have to change occupations in order for the occupational distribution to equal that in area 2, that is, to reduce occupational segregation to zero. The index does not indicate the direction of the segregation, only the degree of dissimilarity of the occupational distributions.

The index of dissimilarity, which became known as the Duncan Dissimilarity Index or simply the D-index, was later adapted to measure race (Gibbs 1965) and gender segregation (Gross 1968). It has become a common measure of segregation, albeit with limitations that have been addressed by various modifications. A key deficiency noted by Bridges (2003) is its sensitivity to the marginal distribution of occupational categories, i.e., a change in the size of the occupational category affects the D-Index even if the gender composition of all occupations remains the same (Preston 2000). The number of occupations also significantly influences the index - the greater the number of occupational categories, the greater will be the D-Index (Fortin and Huberman 2002a).

Refinements to the D-Index measures have included ways of improving the measurement of segregation and "decomposing" it (Beller 1982; Blau and Hendricks 1978; 
Hutchens 2004; Fox and Fox 1987; Rawlston and Spriggs 2002; Spriggs and Williams 1996). The innovation by Spriggs and Williams (1996) was a multivariate analysis that allows simultaneous consideration of a number of determinants of occupational segregation in computing a new index, the L-index.

The Gini Concentration Ratio, commonly referred to as the index of diversity, is a popular index used to measure income inequality. Silber $(1989,1992)$ suggested that the index of diversity could be easily adapted to the measurement of occupational segregation, giving the G-index, or Gs, as a new index of measurement; other uses of this new index followed (Boisso et al. 1994; Carlson 1992).

Hutchens (2001, 2004), in the context of proposing eight desirable properties of a numerical measure of segregation, notes that all measures of segregation agree on what constitutes complete segregation and what constitutes complete integration (corresponding to values of 1 and 0 , respectively). It is the discernment of degrees of segregation and comparisons over time that reveal shortcomings of the D-Index. ${ }^{2}$ Both the Gini coefficient and the D-Index fall short of having the desirable properties in key ways, with the D-Index violating the important property that a segregation measure should consistently perceive a disequalizing move as an increase in segregation.

The empirical studies of the size and determinants of measures of segregation have variously reported modestly decreasing or very resilient and even increasing levels of occupational segregation (Gross 1968; Blau and Hendricks 1978; Fortin and Huberman 2002a; Preston 2000). In the techniques that permit inference about individual characteristics that are key determinants of occupational choice and therefore of occupational segregation, education levels, age of the individual, and location have generally proven to be significant (Albelda 1986; King 1992; Spriggs and Williams 1996).

\section{EMPIRICAL MODEL}

While limitations of the D-Index are acknowledged, this simple index is the most frequently used and is straightforwardly understood. The index value can be readily interpreted to indicate the percentage of the female (male) labor force that would have to change occupations in order for the segregation to disappear.

If the value is .60 , for example, this means that 40 percent of the women (or men) would have to change occupations to eliminate occupational segregation. Thus, while there are indices with more desirable characteristics (Hutchens 2001, 2004), the simple

\footnotetext{
${ }^{2}$ It is not only the D-Index that fails the test of the eight desirable properties. Indeed, none of the existing measures passes the test, thus Hutchens (2004) proposes a square-root index that satisfies seven of the eight properties.
} 
D-Index was chosen to represent occupational segregation. Initially, simple D-Indexes were computed for each region: ${ }^{3}$

$$
D_{r}=\frac{1}{2} * \sum_{i=1}^{k}\left|\frac{M_{i r}}{M_{r}}-\frac{F_{i r}}{F_{r}}\right|
$$

where:

$D_{r}=$ the occupational segregation index for region $r$;

$M_{i r} / M_{r}=$ the proportion of the male labor force in occupation $i$ in region $r$; and $F_{i r} / F_{r}=$ the proportion of the female labor force in occupation $i$ in region $r$.

The absolute value of the sum of the differences between the percentage distributions of males and females in each occupation is divided by two (because there are two groupsmales and females) to yield an index potentially ranging in value from 0 (complete integration) to 1 (complete segregation).

To provide a context for the subsequent investigation, the D-Index values for census years 1986 to 2001 for the 10 Canadian provinces are reported in Table $1 .^{4}$ The values are sorted in ascending order for 2001. In each year the values for Ontario and Quebec, the provinces with the largest metropolitan areas, have index values below the national average, while the provinces/territories that are the most rural/remote have the highest values. Only two provinces, British Columbia and Newfoundland, experienced a substantial change in their relative positions over the observation time period.

Aside from the relative position of provinces, the other striking feature is the stability of the index values. For two provinces, Quebec and New Brunswick, the index values for 2001 are actually greater than for 1986, while for most provinces and for Canada as a whole, there is a modest decline in the values over the 15 year time interval.

To investigate the apparent patterns further, especially with respect to rural-urban differences, occupational segregation determinants are conceptually specified as follows. ${ }^{5}$

\footnotetext{
${ }^{3}$ The square-root index proposed by Hutchens (2001, 2004) was also computed for comparability. The square- root index had about half the value of the D-Index; and while there was not a perfect rank-ordering between them, the correlation was .92. The mean value of the square-root index was .26, ranging from .12 to .47, while the mean D-Index was .53, ranging from .34 to .79. It is thus felt that the influence of the explanatory variables proposed here would be a reasonable representation of occupational segregation, whether measured by the D-Index or the square-root index.

${ }^{4}$ D-Indexes computed over time must be interpreted with caution, given the evolution of given occupational categories as well as the emergence of new categories. What appears as persistent occupational segregation may be partially a function of the underlying data generating processes.

${ }^{5}$ Note that the detailed investigation is undertaken without a time dimension since the focus is on the spatial rather than the intertemporal pattern.
} 
The Review of Regional Studies, Vol. 36, No. 1, 2006, pp. 44-62

TABLE 1

Occupational Segregation D-Index Values: 10 Occupational Groupings

\begin{tabular}{lcccc} 
Province/Territory & $\mathbf{1 9 8 6}$ & $\mathbf{1 9 9 1}$ & $\mathbf{1 9 9 6}$ & $\mathbf{2 0 0 1}$ \\
\hline Ontario & 0.4164 & 0.4008 & 0.4047 & 0.4023 \\
Quebec & 0.4118 & 0.4090 & 0.4061 & 0.4125 \\
Canada & $\mathbf{0 . 4 3 6 2}$ & $\mathbf{0 . 4 2 8 0}$ & $\mathbf{0 . 4 2 8 4}$ & $\mathbf{0 . 4 2 5 6}$ \\
British Columbia & 0.4667 & 0.4681 & 0.4473 & 0.4318 \\
Manitoba & 0.4569 & 0.4516 & 0.4502 & 0.4421 \\
Yukon Territory & 0.4945 & 0.4845 & 0.4653 & 0.4424 \\
Nova Scotia & 0.4679 & 0.4654 & 0.4618 & 0.4548 \\
Alberta & 0.4881 & 0.4746 & 0.4746 & 0.4757 \\
Newfoundland & 0.5142 & 0.5021 & 0.5009 & 0.4774 \\
Prince Edward Island & 0.4921 & 0.4941 & 0.4649 & 0.4790 \\
New Brunswick & 0.4797 & 0.4968 & 0.4881 & 0.4818 \\
Northwest Territories & 0.5210 & 0.4922 & 0.4921 & 0.4824 \\
Saskatchewan & 0.5044 & 0.4920 & 0.4926 & 0.4843 \\
\hline
\end{tabular}

$$
D_{r}=f\left(R_{r}, L M_{r}, H C_{r}\right)
$$

where:

$D_{r}=$ the measure of occupational segregation by gender for region $r$;

$R_{r}=$ a measure of spatial or location characteristics, here rurality of region $r$;

$L M_{\mathrm{r}}=$ labor market characteristics in region $r$; and

$H C_{r}=$ the human capital characteristics of the region $r$ labor force.

The location or spatial characteristic of interest here is the rural or urban nature of the region, hypothesized to be influential because of the role of distance in determining the time and pecuniary costs associated with labor force participation, child care access, and general access to goods and services. The more rural/remote the region, the more distance will increase barriers to labor force participation in general. These barriers may influence women differently than men in occupation choice as flexibility and intensity of demands associated with particular occupations may play different roles.

Labor market characteristics will include the industrial distribution of the labor force, expected to be influential in that primary occupations (agriculture, fishing, forestry, and mining) are more likely to be male dominated due to the historical importance of physical size and strength as well as traditionally entrenched roles. The relative importance of other sectors, especially manufacturing and services, will increase the diversity in the occupational choices beyond the primary sector. Services sector occupations continue to be dominant for females (Fortin and Huberman 2002a). Also included in labor market characteristics will be the female labor force participation rate or the prominence of women in the labor force. 
Human capital variables will potentially include education levels, the presence of children, and the age and experience of the labor force. A gap in educational attainment of males and females would represent differences in human capital as an explanation for occupational segregation. The presence of children may be a determinant to the extent that child care responsibilities are distributed unevenly between males and females and may influence occupational choice. Age is potentially important because it may represent labor force experience and because both occupational choice and participation rates have strong generational components.

\section{DATA SOURCES AND METHODOLOGY}

\subsection{Data Sources}

Occupational distributions for males and females for each of 288 census divisions in Canada for 2000 are available from the 2001 Population Census at two levels of aggregation-47 and 10 occupational categories (Statistics Canada 2001). Employment by industry, number of children by family, educational attainment, and male-female distribution of the labor force were likewise available from the 2001 Census.

Rural-urban indicators were provided by Ray Bollman, Statistics Canada (2004). They are based on an OECD typology of regions designed to reflect the degree to which a region is rural and modified by Statistics Canada. ${ }^{6}$ The five categories for rural-urban region indicators are: predominantly urban, intermediate, rural metro-adjacent, rural nonmetro-adjacent, and rural north. Census divisions are "regions" that were assigned this regional typology.

D-Indexes were computed for each of the 288 census divisions, based on the occupational distributions of males and females. In all cases the more disaggregated-occupation (47 groups) D-Index values were greater than those based on 10 occupational groups, as expected. D-Index values for the 47 occupational grouping, computed for each of Canada's 288 census divisions, are summarized in Table 2.

\footnotetext{
${ }^{6}$ OECD (1994) sets out the basic methodology. Predominantly Rural Regions refer to populations where more than 50 percent of the population lives in a rural community, which is defined as having a population density of less than 150 people per square kilometer. Intermediate regions are those with between 15 and 50 percent of the population living in a rural community. Predominantly urban regions are those with less than 15 percent of the population living in a rural community. To recognize the diversity in the predominantly rural regions category in Canada, Statistics Canada has identified three sub-groups using a Beale Code approach-those adjacent to metropolitan centers, those not adjacent, and northern regions (du Plessis et al. 2002).
} 
TABLE 2

Occupational Segregation D-Index Values: 47 Occupational Groupings

\begin{tabular}{lcccc}
\hline Province/Territory & $\mathbf{1 9 8 6}$ & $\mathbf{1 9 9 1}$ & $\mathbf{1 9 9 6}$ & $\mathbf{2 0 0 1}$ \\
\hline Ontario & 0.4164 & 0.4008 & 0.4047 & 0.4023 \\
Quebec & 0.4118 & 0.4090 & 0.4061 & 0.4125 \\
Canada & $\mathbf{0 . 4 3 6 2}$ & $\mathbf{0 . 4 2 8 0}$ & $\mathbf{0 . 4 2 8 4}$ & $\mathbf{0 . 4 2 5 6}$ \\
British Columbia & 0.4667 & 0.4681 & 0.4473 & 0.4318 \\
Manitoba & 0.4569 & 0.4516 & 0.4502 & 0.4421 \\
Yukon Territory & 0.4945 & 0.4845 & 0.4653 & 0.4424 \\
Nova Scotia & 0.4679 & 0.4654 & 0.4618 & 0.4548 \\
Alberta & 0.4881 & 0.4746 & 0.4746 & 0.4757 \\
Newfoundland & 0.5142 & 0.5021 & 0.5009 & 0.4774 \\
Prince Edward Island & 0.4921 & 0.4941 & 0.4649 & 0.4790 \\
New Brunswick & 0.4797 & 0.4968 & 0.4881 & 0.4818 \\
Northwest Territories & 0.5210 & 0.4922 & 0.4921 & 0.4824 \\
Saskatchewan & 0.5044 & 0.4920 & 0.4926 & 0.4843 \\
\hline
\end{tabular}

\subsection{Methodology}

The estimated equation was:

$$
D_{r}=b_{1}+b_{2} R_{r}+b_{3} P I_{r}+b_{4} M F G_{r}+b_{5} E D_{r}+b_{6} C H_{r}+b_{7} P L F F_{r}+e
$$

where:

$D_{r}=$ D-Index of occupational segregation by gender for region $r$;

$R_{r}=$ the measure of rurality;

$P I_{r}=$ the percentage of the labor force that is employed in primary industries;

$M F G_{r}=$ the percentage of the labor force that is employed in manufacturing;

$E D_{r}=$ the difference in the percentage of males and females (M-F) who have post-high school education/training;

$\mathrm{CH}_{r}=$ the percentage of labor force members in the region with children at home;

$P L F F_{r}=$ the percentage of the labor force that is female; and

$e=$ the error term, assumed normally distributed.

Of the 288 census divisions in Canada, 117, or 41 percent, are rural non-metroadjacent. The mean D-Index values increase monotonically from urban through the northern census divisions, although the distributions overlap due to considerable variation within each group. Table 3 shows descriptive statistics for the labor force characteristics employed in the model as well as selected additional variables.

The fixed effect of the location was represented by rurality of each census division using the OECD rural typology, resulting in four dummy variables, where "predominantly urban" was the omitted category. 
TABLE 3

\begin{tabular}{lcc}
\multicolumn{3}{c}{ Descriptive Statistics, Selected Labor Force Variables, 2001} \\
\hline Variable & Mean & Standard Deviation \\
\hline D-Index Major Groups (10) & 0.4969 & 0.0650 \\
D-Index Disaggregated Occupations (47) & 0.5341 & 0.0613 \\
Percent of Labor Force in Primary (PI) & 0.1123 & 0.0912 \\
Percent of Labor Force in Manufacturing (MFG) & 0.1408 & 0.0829 \\
Percent of Labor Force in Services & 0.4806 & 0.0896 \\
Percent of Females with Post-Secondary Ed & 0.4669 & 0.0752 \\
Percent of Males with Post-Secondary Ed & 0.4633 & 0.0861 \\
Male-Female \% w. Post-Secondary Ed. (ED) & -0.0037 & 0.0270 \\
Percent of Labor Force with Children at Home (CH) & 0.4861 & 0.0399 \\
Percent of Labor Force that is Female (PLFF) & 0.4509 & 0.0306 \\
Percent of Labor Force Aged 25-44 & 0.3575 & 0.0481 \\
\hline Source: Statistics Canada, 2002, Census of Population \\
\hline
\end{tabular}

Labor market characteristics in the model include two variables to represent the industrial distribution of the labor force in each region: the percentage of the labor force in primary industries and the percentage of the labor force in manufacturing industries. The percentage of the labor force in the services sector could not be included along with primary and manufacturing due to the problem of a near-singular matrix. The percentage of the labor force comprised of women, calculated for each census division, was included to represent female labor force participation.

Human capital variables included education and number of children. An education gap between males and females was computed as follows. The percentage of the labor force with some post-high school education was calculated for males and females in the region. The difference between the two percentages (M-F) was used to represent the education gap in each region. The presence of children is measured by the percentage of labor force members that have children at home.

Other explanatory variables that were considered were: fixed effects for the provinces and percentage of the labor force in the prime age workforce (ages 25-44). Provincial fixed effects ${ }^{7}$ were not included in the final specification for the following reasons. With the exception of the most remote northern regions, the provincial fixed effects were not significant. Further, since there is little variation in the OECD typology within provinces with the exception of Ontario, the inclusion of the provincial dummies reduced the significance of the rural dummies. Third, employment equity policies,

\footnotetext{
${ }^{7}$ The fixed-effects specification included dummies for each province, with Ontario (the lowest Dindex) being excluded. While the provincial dummies were mostly not significant individually (based on t-tests), comparison of the "restricted" model with the unrestricted (with provincial dummies) revealed that the null hypothesis of the coefficients all being equal to zero could be rejected, implying that jointly the provincial dummies contributed to the explanation of occupational segregation. However, when the provincial fixed effects were included, most of the other coefficients were insignificant, their influence being washed out by the fixed effects variables.
} 
legislation, and programs among the provinces and territories, though different in detail, have very similar objectives. ${ }^{8}$ The final specification reflects the primary focus on "rural" in this paper. The inclusion of a prime-age work force variable (percent of the labor force in the 25-44 age group) was very highly correlated with the presence of children, so a choice was made to use the presence of children variable.

The nature of the D-Index suggests a logistical specification. However, since the value of the index is confined to a fairly narrow range from .40 to .70, for observations in the current data set, and indeed globally, a linear approximation is used. Ordinary Least Squares (OLS), using the E-Views software, was used to run the regressions.

The OLS regressions were run for both D-Indexes calculated for the 10-occupation grouping and the 47-occupation grouping. In all cases the 47 occupation grouping resulted in better statistical outcomes.

\section{RESULTS}

The estimation results for Equation 3 above are presented in Table 4. All four dummy variables specified to capture the influence of being in a rural region are of the expected sign and highly significant, showing a higher level of occupational segregation in rural areas relative to urban. Overall, the varying degrees of rurality differ from urban regions by similar amounts, varying from .019 (northern) to .023 (rural non-metroadjacent). ${ }^{9}$ Relative to urban, the rural non-metro-adjacent location will increase the occupational segregation index by .023. Given the average segregation index for urban regions of .4492, this represents a 5 percent increase. Rural non-metro-adjacent regions are the most disparate from predominantly urban regions, as would be expected.

Explanatory variables, except perhaps for education, are of the expected sign and are significant at greater than the 1 percent level. The presence of children increases occupational segregation, ceteris paribus. A 10 percent increase in the percent of the labor force with children (a .10 increase in the value of $\mathrm{CH}$ ) would lead to a .0338 increase in the D-Index, approximately a 6 percent increase (relative to the average of .534). Occupational segregation is higher the lower the percentage of the labor force comprised of

\footnotetext{
${ }^{8}$ The basis for most employment equity initiatives in Canada is Human Rights legislation. There is also the Federal Equity Statute that applies to federal government employees and the federally regulated private sector. In combination this legislation/set of regulations governs employment equity initiatives in the provinces.

${ }^{9}$ A restricted model with all rural coefficients set equal to each other was estimated. An F-test of the significance of the difference between the two estimations indicated that the null hypothesis of equality of the rural coefficients could be rejected at the 1 percent level of significance.
} 
TABLE 4

\begin{tabular}{lcccc}
\multicolumn{5}{l}{ Estimated Coefficients, D-Index (47 occupations) regression, Equation 3, OLS } \\
\hline Variable & Coefficient & Std. Error & t-Statistic & Prob. \\
\hline C & 0.466349 & 0.057403 & 8.124186 & 0.0000 \\
R1 (Intermediate) & 0.022471 & 0.005680 & 3.955908 & 0.0001 \\
R2 (Rural metro-adj.) & 0.021034 & 0.003515 & 5.984092 & 0.0000 \\
R3 (Rural non-metro-adj.) & 0.023748 & 0.002677 & 8.872755 & 0.0000 \\
R4 (Northern) & 0.019153 & 0.002738 & 6.994877 & 0.0000 \\
CH & 0.317844 & 0.071035 & 4.474475 & 0.0000 \\
ED & 0.164138 & 0.078425 & 2.092943 & 0.0373 \\
PLFF & -0.337242 & 0.091412 & -3.689246 & 0.0003 \\
PI & 0.098756 & 0.036533 & 2.703213 & 0.0073 \\
MFG & -0.110596 & 0.035878 & -3.082568 & 0.0023 \\
\hline N $=288$ & & & & \\
R-squared $=0.496$ & & & & \\
\hline
\end{tabular}

women, ${ }^{10}$ the greater the prevalence of primary industries, and the lower the proportion of total employment accounted for by manufacturing.

The coefficient of the education gap variable is significant and positive, implying that the smaller the gap the lesser the occupational segregation, as would be expected $a$ priori. It should be noted, however, that on average, educational attainment of females is higher than that of males. On average, over all region types, the percentage of females with some post-secondary education is .37 percent greater than the percentage of males. Averages by regional typology reveal little by way of a regional pattern (Table 5). Given the overall negative values of the male-minus-female educational attainment, one might expect a negative coefficient - the more negative the gap, the greater the occupational segregation. This interpretation, however, assumes that the fields of education and employment are similar for males and females, an assumption that is not likely realistic. With women more concentrated in professional occupations (teachers and nurses) and males more concentrated in the trades, the education gap in aggregate does not well represent these sources of occupational segregation. Given the simplicity of the education measure, the coefficient cannot be interpreted in a straightforward way.

A possible explanation of the above findings is that an education advantage by females is required for equal representation in occupations and that the greater this advantage (the larger the negative the gap), the lesser will be occupational segregation. Overcoming other factors mitigating against full participation of females in the labor

\footnotetext{
${ }^{10}$ Because of the potential endogeneity between labor force participation of women (here the percent of the labor force that is female) and occupational segregation, the regression was also run with the participation variable omitted. Since there was very little difference in the size or significance of the coefficients, the variable was retained.
} 
TABLE 5

Differences in Male-Minus-Female Percentage of the Labor Force with Some Post-Secondary Education, by Regional Typology

\begin{tabular}{|c|c|c|c|c|c|c|}
\hline & Urban & Intermediate & $\begin{array}{c}\text { Rural- } \\
\text { Metro- } \\
\text { Adjacent }\end{array}$ & $\begin{array}{c}\text { Rural Non- } \\
\text { Metro- } \\
\text { Adjacent }\end{array}$ & Northern & $\begin{array}{c}\text { All } \\
\text { Regions }\end{array}$ \\
\hline Mean diff in \% & -0.22 & -0.42 & 0.76 & -1.22 & -0.21 & -0.37 \\
\hline Min. diff. & -8.11 & -7.93 & -7.63 & -11.09 & -3.04 & -11.09 \\
\hline Max. diff. & 8.57 & 7.65 & 8.18 & 6.91 & 3.91 & 8.57 \\
\hline No. of obs. & 27 & 38 & 83 & 117 & 23 & 288 \\
\hline
\end{tabular}

force may require a higher, rather than equal, level of educational attainment on the part of females. ${ }^{11}$

\section{CONCLUSIONS AND IMPLICATIONS}

Occupational segregation of males and females remains a prominent feature of most OECD countries and is the basis for concerns about the equality of labor market outcomes. Employment equity, pay equity, and/or affirmative action programs and policies are in place in most countries to address segregation, based on a number of social and economic policy objectives. Economic concerns relate to inefficient use of resources and welfare losses associated with barriers to factor mobility. Segregation unexplained by human capital variables or preferences (to the extent that they can be inferred) may reflect systemic bias and discrimination.

Public policy initiatives designed to address the root causes of segregation include attempts to equalize education levels to address human capital differences. As the above data show, education attainment is now higher, on average, for women than for men in Canada. This does not, of course, address the question of the particular fields/areas of training/education. Improving child care access and quality of services are additional public policy initiatives that may be expected to influence labor force participation rates and occupational choices of males and females. Employment equity or affirmative action programs would be most appropriate to address systemic discrimination.

The model estimated in this paper represents an explicit consideration of the influence of a number of standard explanatory variables on a commonly used occupational segregation index - the D-Index. The results confirm expectations with respect to the effect of the presence of children, the industrial mix of the labor force, and the participation level of females.

The spatial variations in occupational segregation revealed in the estimations suggest a source of occupational segregation that has been largely overlooked. Specifically, the

${ }^{11}$ Equation 3 was also estimated using the absolute value of the M-F difference in educational attainment. The result was a negative coefficient, though significant only at the 28 percent level. 
rurality of a region contributes significantly to the occupational segregation of its labor force, even after controlling for differences in the industrial distribution of the local economy, the presence of children, educational attainment gaps, and female participation levels. Relative to urban, rural regions have significantly more occupational segregation for all four categories of rural investigated here.

The interpretation of the rural dimension of occupational segregation may be found in the recognition that the cost (time and expense) of distance has an influence on occupational choice and that this influence is different for males and females. Other explanations include the relative scarcity of employment opportunities in rural areas, greater difficulties in coordinating employment for two-income earner families, and perhaps more traditional views with respect to employment roles of males and females.

The research findings represent a "snapshot" of rural-urban differences in the occupational segregation, defined by the D-Index, for one point in time. Should the findings presented here prove to be stable over time, the policy implications are that the usual means of addressing occupational segregation may not be equally effective in rural and urban areas. A more targeted approach designed to specifically address the differential nature of occupational segregation in rural areas may be required. Policy initiatives to mitigate the uniquely binding effect of distance for women may be considered to reduce occupational segregation.

Further research is required to test the findings presented here using different measures of occupational segregation and more refined spatial variations, perhaps allowing distance to urban centers to vary in a continuous way. Intertemporal results would be informative as to the size and direction of change over time. Also, the relationship between occupational segregation and education requires further investigation to refine our understanding of the role of human capital and how this may be different for males and females as well as rural and urban areas.

\section{REFERENCES}

Agocs, C., 2002. “Canada’s Employment Equity Legislation and Policy, 1987-2000,” International Journal of Manpower 23(3), 256-276.

Albelda, R., 1986. "Occupational Segregation by Race and Gender, 1958-1981," Industrial and Labor Relations Review 39, 401-411.

Anker, R., 1997. "Theories of Occupational Segregation by Sex: An Overview," International Labor Review 136(3), 315-325.

Averitt, R.T., 1968. The Dual Economy: The Dynamics of American Industry Structure. W.W. Norton: New York.

Beck, E.M., P.M. Horan, and C.M. Tolbert II, 1980. "Industrial Segmentation and Labor Market Discrimination,” Social Problems 28, 113-130.

Becker, G.S., 1965. "A Theory of the Allocation of Time,” The Economic Journal 75, 493-517. 
1975. Human Capital: A Theoretical and Empirical Analysis, with Special Reference to Education. Columbia University Press: New York.

, 1985. "Human Capital, Effort, and the Sexual Division of Labor," Journal of Labor Economics 3(1), S33-S58.

Beller, A.H., 1982. "Occupational Segregation By Sex: Determinants and Changes,” The Journal of Human Resources 17(3), 371-392.

Bergmann, B., 1974. "Occupational Segregation, Wages and Profits When Employers Discriminate by Race or Sex,” Eastern Economic Journal 1, 103-110.

Blau, F.D. and W.E. Hendricks, 1978. "Occupational Segregation by Sex: Trends and Prospects,” The Journal of Human Resources 14(2), 196-210.

Blinder, A.S. and Y. Weiss, 1976. "Human Capital and Labor Supply: A Synthesis," Journal of Political Economy 84(3), 449-472.

Bloomquist, L.E., 1990. "Local Labor Market Characteristics and the Occupational Concentration of Different Sociodemographic Groups,” Rural Sociology 55(2), 199213.

Boisso, D., K. Hayes, J. Hirschberg, and J. Silber, 1994. “Occupational Segregation in the Multidimensional Case,” Journal of Econometrics 61, 161-171.

Bokemeier, J.L., C. Sachs, and V. Keith, 1983. "Labor Force Participation of Metropolitan, Nonmetropolitan, and Farm Women: A Comparative Study," Rural Sociology 48(4), 515-539.

Bollman, R., Statistics Canada, Agriculture Division, 2004. Personal communication regarding census division classification.

Bridges, W.P., 2003. "Rethinking Gender Segregation and Gender Inequality: Measures and Meanings,” Demography 40(3), 543-568.

Brown, R.S., M. Moon, and B.S. Zoloth, 1980. "Incorporating Occupational Attainment in Studies of Male-Female Earnings Differentials," The Journal of Human Resources 15(1), 3-28.

Carlson, S.M., 1992. "Trends in Race/Sex Occupational Inequality: Conceptual and Measurement Issues,” Social Problems 39(3), 268-290.

Deseran, F.A., J.H. Li, and R.A. Wojtkiewicz, 1993. "Household Structure, Labor Market Characteristics, and Female Labor Force Participation,” in J. Singlemann and F.A. Deseran (eds.), Inequalities in Labor Market Areas. Westview Press, Inc.: Boulder, CO.

Doeringer, P.B. and M.J. Piore, 1971. Internal Labor Markets and Manpower Analysis. D.C. Heath: Lexington, MA.

du Plessis, V., R. Beshiri, R.D. Bollman, and H. Clemenson, 2002. "Definition of 'Rural'.” Statistics Canada Agriculture and Rural Working Paper Series, Working Paper No. 61.

Duncan, O.D. and B. Duncan, 1955. "Residential Distribution and Occupational Stratification," The American Journal of Sociology 60, 493-503.

Fortin, N.M. and M. Huberman, 2002a. "Occupational Gender Segregation and Women’s Wages in Canada: An Historical Perspective," Canadian Public Policy 28 (supplement), S11-S39.

, 2002b. "Occupational Gender Segregation: Public Policies and Economic Forces, Introduction and Overview,” Canadian Public Policy 28 (supplement), S1-S10. 
Fox, B.J. and J. Fox, 1987. Occupational Gender Segregation of the Canadian Labor Force 1931 - 1981. University of Toronto Press: Toronto.

Freeman, R.B., 2000. "The Feminization of Work in the USA: A New Era for (Man)kind?” in S.S. Gustafsson and D.E. Meulders (eds.), Gender and the Labor Market: Econometric Evidence of Obstacles to Achieving Gender Equality. St. Martin's Press: New York.

Fuchs, V.R., 1989. “Women's Quest for Economic Equality,” Journal of Economic Perspectives 3, 25-41.

Gibbs, J.P., 1965. "Occupational Differentiation of Negroes and Whites in the United States,” Social Forces 44(2), 159-165.

Glaister, R.J., 1977. Income and Employment Among the Native Indian Population in Manitoba: A Comparison of Human Capital and Dual Labor Market Theories. University of Manitoba, Master's Thesis (MA): Winnipeg.

Gronau R., 1977. "Leisure, Home Production and Work: The Theory of the Allocation of Time Revisited,” Journal of Political Economy 85, 1099-1123.

Gross, E., 1968. "Plus Ca Change...? The Sexual Structure of Occupations Over Time,” Social Problems 16, 198-208.

Honig, M. and G. Hanoch, 1978. "The Labor Supply Curve Under Income Maintenance Programs,” Journal of Public Economics 9, 1-16.

Hutchens, R., 2001. "Numerical Measures of Segregation: Desirable Properties and Their Implications," Mathematical Social Sciences 42, 13-29.

, 2004. "One Measure of Segregation,” International Economic Review 45, 555578.

Kidd, M.P. and M. Shannon, 1994. "An Update and Extension of the Canadian Evidence on Gender Wage Differentials,” Canadian Journal of Economics 27(4), 918-938.

King, M., 1992. “Occupational Segregation by Race and Gender, 1940-1988,” Monthly Labor Review 115, 30-36.

Kooreman, P. and A. Kapteyn, 1987. "A Disaggregated Analysis of the Allocation of Time Within the Household,” Journal of Political Economy 95, 223-249.

Maruani, M., 2000. "Women's Employment in a Society of Rampant Unemployment," in S.S. Gustafsson and D.E. Meulders (eds.), Gender and the Labor Market: Econometric Evidence of Obstacles to Achieving Gender Equality. St. Martin's Press: New York.

McGoldrick, K.M. and J. Robst, 1996. "Gender Differences in Overeducation: A Test of the Theory of Differential Overqualification," The American Economic Review Papers and Proceedings 86, 280-284.

Meng, X. and P. Miller, 1995. "Occupational Segregation and its Impact on Gender Wage Discrimination in China's Rural Industrial Sector," Oxford Economic Papers 47, 136-155.

Mincer, J. and S. Polachek, 1974. "Family Investments in Human Capital: Earnings of Women,” Journal of Political Economy 82(2), S76-S108.

Norcliffe, G., 1993. "Regional Labor Market Adjustments in a Period of Structural Transformation: An Assessment of the Canadian Case," The Canadian Geographer 38(1), 2-17. 
OECD, 1994. Creating Rural Indicators for Shaping Territorial Policy/Créer des Indicateurs Ruraux pour Étayer la Politique Territoriale. Organization for Economic Cooperation and Development: Paris.

Preston, A., 1997. "Where Are We Now with Human Capital Theory in Australia?” The Economic Record 73(220), 51-78. , 2003. "Women's Work in Australia: Trends Issues and Prospects," Australian Journal of Labor Economics 6(4), 497-518.

— 2004. "Gender Differences in Occupation Employment within Australia," Australian Journal of Labor Economics 7(3), 309-327.

Preston, J.A., 2000. "Occupational Gender Segregation Trends and Explanations,” The Quarterly Review of Economics and Finance 39, 611-624.

Rawlston, V. and W.E. Spriggs, 2002. "A Logit Decomposition Analysis of Occupational Segregation: An Update for the 1990s of Spriggs and Williams," Review of Black Political Economy 29(4), 91-96.

Robinson, C. and N. Tomes, 1985. "More of the Labor Supply of Canadian Women," Canadian Journal of Economics 18(1), 156-163.

Schultz, T.W., 1961. "Investment in Human Capital," The American Economic Review 51(1), 1-17.

Silber, J., 1989. "Factor Components, Population Subgroups and the Compilation of the Gini Index of Inequality,” Review of Economics and Statistics 71(1), 107-115. , 1992. "Occupational Segregation Indices in the Multidimensional Case: A Note," Economic Record 68(202), 276-277.

Spriggs, W.E. and R.M. Williams, 1996. "A Logit Decomposition Analysis of Occupational Segregation: Results for the 1970s and 1980s," The Review of Economics and Statistics 78, 348-354.

Statistics Canada, 2001. Population Census for 2001. Statistics Canada: Ottawa.

Villa, P., 1986. The Structuring of Labor Markets: A Comparative Analysis of the Steel and Construction Industries. Clarendon Press: Oxford.

Walby, S., 1988. "Segregation in Employment in Social and Economic Theory,” in S. Walby (ed.), Gender Segregation at Work. Open University Press: Philadelphia. 